\title{
A cultural historical activity theory (CHAT) analysis of prehospital emergency medical care clinical mentorship to enable learning
}

\author{
N Liebenberg, ${ }^{1}$ MEMC, HDHET; L Christopher, ${ }^{2}$ MTech: EMC; J Garraway, ${ }^{3}$ DPhil \\ ${ }^{1}$ Lebone College of Emergency Care, Department of Health, Gauteng Provincial Government, Pretoria, South Africa \\ ${ }^{2}$ Department of Emergency Medical Sciences, Faculty of Health and Wellness, Cape Peninsula University of Technology, Bellville Campus, Cape Town, South Africa \\ ${ }^{3}$ Fundani Centre for Higher Education, Cape Peninsula University of Technology, Bellville Campus, Cape Town, South Africa
}

Corresponding author: N Liebenberg (nuraan.jacobs@gmail.com)

\begin{abstract}
Background. Clinical mentorship in health sciences education is a nurtured venture where mentees are guided through practice by their more experienced mentors. However, recent research suggests that there are problems with clinical mentorship.

Objective. To explore problems in work-integrated learning within the mentor/mentee relationship.

Methods. The cultural historical activity theory (CHAT) was used to interpret data gathered from diaries and focus group interviews.

Results. Difficulties identified were poor communication between the university and the mentors at clinical platform sites. The unclear roles and responsibilities of mentees and mentors led to a breakdown of trust.

Conclusions. Better university training and development of mentors would aid in the holistic development of mentors and mentees.
\end{abstract}

Afr J Health Professions Educ 2019;11(4):111-113. https://doi.org/10.7196/AJHPE.2019.v11i4.1138

Mentorship in health sciences education and thus in prehospital emergency medical care should be a nurtured, guided venture led by an experienced mentor. In most instances, mentees from higher education institutions are placed on the clinical platform in emergency medical services, hospitals and clinics, where they are mentored by qualified, registered healthcare practitioners. Recent research indicates that there are problems with mentor/mentee relationships in health sciences education. The relationship between mentees and mentors as analysed within an activity system illustrated the difficulties within clinical mentorship.

\section{Research design and methods}

A qualitative study was conducted using the cultural historical activity theory (CHAT) as the interpretive framework to identify, elucidate and exemplify the elements of the clinical mentorship system and thus indicate difficulties and opportunities for change.

In performing the CHAT analysis, the clinical mentorship system was split into various elements: subject, object, tools and signs, rules, division of labour (DoL) and community. The subject in this activity system is the mentee, who is guided by the mentor. The object of the system is preparation of mentees for the real world of work. Tools and signs are identified as physical material, such as equipment, and non-physical material, such as knowledge of the mentor or community member (any person involved with or invested in the object of the activity system). The subject uses these tools to work on the object. The rules are formal, such as processes governing practice, including the scope of practice as determined by the Health Professions Council of South Africa (SA), and informal, such as workplace cultural practices and trust. The DoL comprises the different roles and responsibilities of mentee and mentor or community member as they work on a common object of the activity. During the analysis, there was a search for contradictions within and between the elements of the system that impede successful working on the object of the activity.
The aim, after identifying the contradictions, was to resolve areas in need of change and development. The participant sample was selected through purposive, convenience sampling that identified student and mentor participants. Five students (mentees) and 5 paramedic practitioners (mentors) consented to participate.

Data were collected through mentees' reflection on significant learning events and difficulties experienced during work-integrated learning (WIL). These were recorded by the mentee in a hand-written diary (provided by the researcher $(\mathrm{NL})$ ). Each mentee recorded a minimum of two 12-hour shifts, which were analysed and interpreted by the researcher. Secondly, focus group interviews were conducted that were guided by elements of CHAT and concepts and matters of interest identified in the diaries. These interviews were held with both mentors and mentees as separate groups and allowed further exploration to develop in-depth accounts of perceptions and experiences. ${ }^{[1]}$

\section{Ethical approval}

Ethical approval was granted by the Cape Peninsula University of Technology, Cape Town, SA (ref. no. CPUT/HW-REC 2013/H26) and the Provincial Department of Health, Western Cape, SA (ref. no. RP 164 /2013).

\section{Results and discussion}

The object of the activity system was understood to be mentee preparation for the world of work, but what was identified and actually happened during clinical mentorship was not necessarily conducive to working on this object. For example, the clinical placement of students during the academic term often set up a conflict within the object, as students focused on preparation for academic assessments rather than on clinical work.

During clinical work, mentors allowed mentees only to observe rather than practise clinical care. A lack of trust between mentor and mentee (informal rule) was conflicted with and constrained by 'who does what' while working on a task (DoL). This created difficulties within the DoL 


\section{Short Research Report}

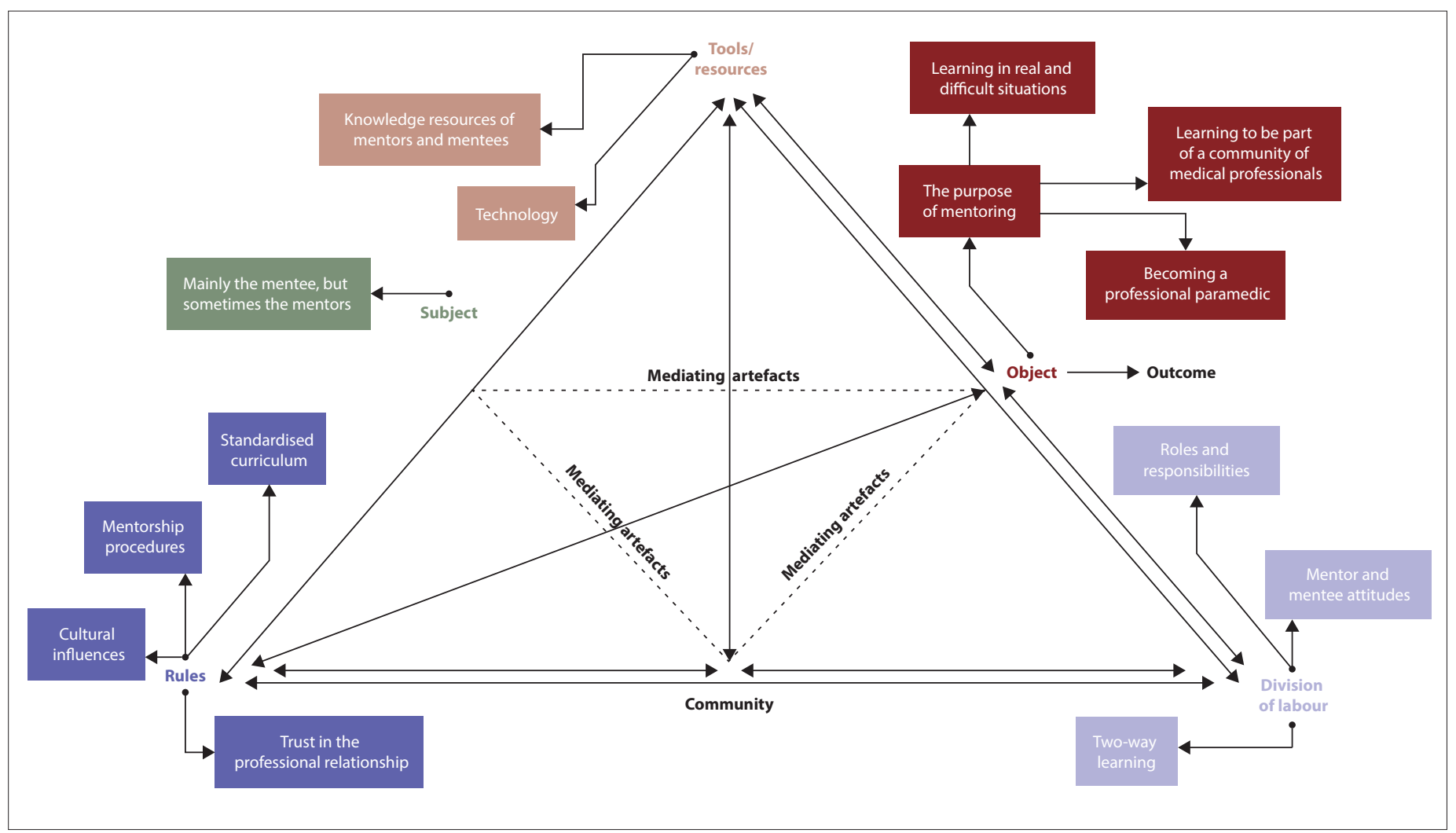

Fig. 1. Cultural historical activity theory (CHAT) illustration of contradictions in the clinical mentorship activity system (adapted from Engeström ${ }^{[2]}$ ).

element (Fig. 1) and constrained mentees' learning, which was the object of the activity system.

A contradiction adding to the constraint of learning was a lack of clear mentorship policy and processes (formal rules) to guide the mentor in the role of working on the object of the activity. Therefore, communication between mentor and mentee was hindered, e.g. mentors were not informed of mentees being assigned to them, or what the expected learning outcomes were for the mentees.

The mentors' knowledge and practice (tools for the mentees) were sometimes outdated and not based on current best practice; therefore, the mentee, using best practice to work on the object of learning, was potentially constrained. Furthermore, a lack of foundational knowledge of mentees (tools) added to problems for both mentors and mentees working on the object of activity.

To resolve the difficulties identified in the clinical mentorship activity system, suggestions are made for improvement and development.

Where trust was lacking, mentors could work with students in the university skills laboratories to obtain an understanding of what the students are capable of doing. In this way mentors could observe students performing complex procedures competently. Stronger mutual participation could also be improved by engagement between students, academics and mentors, perhaps through shared online sites where problems can be discussed. This would serve to improve communication. A manual on teaching/mentoring, and a short course, could be developed for mentors. This could be part of the continuing professional development of mentors, as well as help to improve mentees' experiences. ${ }^{[3,4]}$ To improve students' tools during clinical mentorship, the curriculum should aid in bridging the theory-practice gap. ${ }^{[5]}$ Students could, for example, do more problem-based work, during which they are specifically expected to challenge what they have learnt, and to adapt and apply knowledge to real-life problems. ${ }^{[6-8]}$

\section{Conclusions}

If the object of the activity system of learning is to become a paramedic, then changes need to be made to the clinical mentoring activity system to realise this object more effectively. This article highlights how changes to tools, rules and DoL elements can enhance learning. The key difficulties identified in the social clinical mentorship activity system were poor communication and understanding of the roles and responsibilities of mentee and mentor, both often leading to a breakdown of trust. A better integration of mentors in the university system would improve the development of mentees.

Declaration. This article is based on a study done by NL in partial fulfilment of her Master's degree in Emergency Medical Care.

Acknowledgements. We acknowledge support, guidance and encouragement from Dr Navindhra Naidoo.

Author contributions. NL: conceived the idea, identified the theory and performed the analysis in consultation with and with guidance from JG and LC. Analytical methods were verified by JG and LC and both encouraged and supervised the findings of this work. All authors discussed the results and contributed to the final manuscript.

Funding. None.

Conflicts of interest. None.

\footnotetext{
1. Cousin G. Researching Learning in Higher Education. An Introduction to Contemporary Methods and Approaches. New York: Routledge, 2009.

2. Engeström Y. Expansive learning at work: Toward an activity theoretical reconceptualization. J Educ Work 2001;14(1):133-156. https://doi.org/10.1080/13639080123238
} 


\section{Short Research Report}

3. Hudson P. Forming the mentor-mentee relationship. Ment Tutor Partner Learn 2016;24(1):1-14. https://doi.org/
10.1080/13611267.2016.1163637
4. Matthew S, Taylor R, Ellis R. Relationships between students' experiences of learning in an undergraduate
internship programme and new graduates' experiences of professional practice. High Educ 2012;64(4):529-542.
5. Gamble J. The relation between knowledge and practice in curriculum and assessment. 2009. https://www.
umalusi.org.za/docs/research/2009/gamble.pdf (accessed 2 August 2019).
6. Michau R, Roberts S, Williams B, Boyle M. An investigation of theory-practice gap in undergraduate paramedic
education. BMC Med Educ 2009;9:23. https://doi.org/10.1186/1472-6920-9-23
7. Billet S. Realising the educational worth of integrating work experiences in higher education. Stud High Educ 2009;34(7):827-843. https://doi.org/10.1080/03075070802706561

. Mcwhirr S, Gordon R. A Holistic View of Formal Mentoring Relationships: Can Activity Theory Bridge the Gap? Aberdeen, UK: Robert Gordon University, 2014:1-2.

Accepted 1 July 2019 